\title{
In Between Hogging and Passing the Mic; Or, the Unintended Consequences of Networked Radio in Ghana
}

\author{
Nii Kotei Nikoi \\ Assistant Professor of Global Media and Digital Studies, Global Media and \\ Digital Studies Program, The College of Wooster, Ohio, USA \\ nnikoi@wooster.edu \\ Seyram Avle \\ Assistant Professor, Global Digital Media, Department of Communication, \\ University of Massachusetts, Amherst, USA \\ savle@umass.edu
}

\begin{abstract}
This paper explores the relationship between networked radio, media participation, and accountability in Ghana. Specifically, we examine how networked radio, the hybrid media space that is the convergence of radio and social media practices, works as a means of democratic accountability through citizen participation in media. We do this through an analysis of how two English-speaking radio stations in Ghana act as intermediaries between citizens and the state, underscoring how the networked elements of radio production facilitate public discourse and make the state less opaque to citizens. We show that while networked radio does provide multiple opportunities for media participation, this participation is relatively passive for the majority of listeners, in part because producers face increased interactivity in-studio and must employ gatekeeping tactics to fit the constraints of airtime. This trade-off inadvertently privileges elite voices over others, even if the radio stations work to diversify the voices heard on air. Still, networked radio provides a limited but necessary alternative to exacting accountability from public officials as those very dynamics of participation elicit the state's responsiveness more regularly than the formal routes established for those purposes. Accordingly, we characterize Ghanaian networked radio as caught between 'hogging the mic' for an elite group of listeners and 'passing the mic' between them, the state, and the broader citizenry that constitute the listening public.
\end{abstract}




\section{Keywords}

networked radio - media participation - accountability - Ghana - democracy

\section{Introduction}

The media's role as the fourth estate within a liberal democracy rests on its ability to function both as a bridge for information between the government and the governed, and as a conduit for holding both public officials and citizens accountable. This role in turn rests on the degree to which the media is independent from undue political influence. In Ghana, where there is a relatively free media, radio remains the primary medium through which citizens and governments interact given the advent of what has been described as networked radio (Avle 2015). Networked radio refers to the hybrid media space that is the convergence of radio and social media practices (Avle 2015; 2016). Through a mix of phone call-ins, text messaging, and social media posts, radio stations and their listeners banter, discuss social and economic issues, and experience radio as a shared space of interaction, both synchronously and asynchronously (Avle 2015; 2016; Coker 2012; Srinivasan and Diepeveen 2018; Tettey 2017).

There is an open question about how networked radio fits within existing expectations of the role that media plays in a functioning democracy. Specifically, how does participation via citizen contributions to media, or 'participation through media' (Wasko and Mosco 1992), provide a net good for a democratic society? A longstanding assumption has been that increased political or civic participation such as voting are robust democratic functions, and a fundamental impetus for participating in these ways is the opportunity for citizens to hold public institutions and officials accountable (Phillip, 2009). Bucy and Gregson (2001) argue that "the experience of media participation is pivotal to maintaining the perception of systems responsiveness and thereby serves as an important legitimizing mechanism for mass democracy" (375). In addition to providing information on government activities and reporting on accountability processes, the media can become the vehicle to trigger changes to formal accountability mechanisms or possibly replace them altogether.

In theory, there should be multiple ways through which citizens hold elected officials accountable outside of voting and media participation. In Ghana, we observe that such avenues exist, for instance through in-person interactions with local officials but are largely inaccessible to the majority. For instance, the first author attempted to participate in a local assembly town hall meeting in 
the Ga East Municipality in Accra in July 2017. Unable to find the scheduling information online, he made an in-person visit to the office to inquire about the schedule but never received one despite speaking with multiple municipal officials on site. This experience was repeated in another municipality, the La-Nkwantanang-Madina Municipal Assembly, showing a systemic challenge to accessing basic information from local government. With no scheduling information, there was no way of being present for any of these announced townhalls. This poses an impediment for civic participation at a fundamental level. In this scenario, a reasonable move might then be to complain to a local radio station in the hopes that the issue might be taken up on-air, given that prior work has shown that radio phone-in programs in Ghana operate as a space for turning individual concerns into a collective resource (Selormey 2013). The resolution of public good calls (as opposed to personal calls) benefits the wider society or community, for example, in this case providing public access to town hall schedules, or in other cases, fixing roads in a community, returning disrupted utilities, etc. Media participation, in this way works to provide an alternate avenue for demanding accountability when existing mechanisms are largely ineffective.

Most Ghanaians obtain their news from radio and television (Afrobarometer 2018) and the media have become a primary mechanism through which citizens experience and engage democratic activity in the country. However, there are concerns about whose voice is able to trigger such accountability through the media (Selormey 2013; Tettey 2017). The public officials, researchers, experts, and social commentators who appear on-air may not be representative of general public sentiment, even if they can operate "as agents or representatives of the broader citizenry" (Page and Tannebaum 1996, 33). The increased access to internet and digital tools in the past decade in Ghana (Tettey 2017) that underpins networked radio provides additional opportunities for media participation while providing an opportunity to observe if new patterns of wrestling accountability emerge. This paper thus focuses on the relationship between networked radio, media participation, and accountability.

We examine the top two English-speaking stations ${ }^{1}$ in Ghana to see what dynamics emerge from citizens participating in networked radio and how they work towards accountability. We begin by first situating the relationship between media, participation and democratic accountability, followed by an overview of the history of Ghanaian media leading up to its liberalization and the emergence of network radio. We then present the research by first explaining our methods, then our thematic analysis before discussing the findings.

1 Ghana is a multilingual country and English is the official language. 
We show that while networked radio does provide multiple opportunities for media participation, this participation is relatively passive for the majority of listeners, in part because producers face increased interactivity in-studio and must employ gate-keeping tactics to fit the constraints of airtime. This inadvertently privileges elite voices over others, even if the radio stations work to diversify the voices heard on-air. Still, networked radio provides a limited but necessary alternative to exacting accountability from public officials as those very dynamics of participation elicit the state's responsiveness more regularly than the formal routes established for those purposes. Accordingly, we characterize Ghanaian networked radio as caught between 'hogging the mic' for an elite group of listeners and 'passing the mic' between them, the state, and the broader citizenry that constitute the listening public.

\section{Media Participation and Democratic Accountability}

Vibrant media participation by citizens in a democratic society has been regarded as an indication of deepening democracy (Loader and Mercea 2012). Drawing on prior work in media studies and political communication (Carpentier 2011, Dahlgren 2009, Jacobs and Schillemans 2016, Loader and Mercea 2012, Mazzoleni and Schulz 1999, Wasko and Mosco 1992), we locate media participation at the nexus of how audiences, as both active or passive citizens and consumers, interact with the media as an industry and institutions as part of the political landscape in a democracy. As citizens, audiences are constructed as belonging to political communities or publics and also consumers or 'brand communities' (Carpentier (2011) within a market framework. There are variations in how this political and economic relationship between the media and their audiences are theorized but we build on the understanding that the media are part of the mechanisms that inform and mediate public discourse.

Mazzoleni and Schulz (1999) argue that the mediatization of politics-politics that has become dependent on media and is shaped by its ongoing interactions - is based on the notion that "mass media produce political content and interfere with political processes" (250). In their view, 1) mediatized politics is shaped by news values, which in turn shape what media is selected and omitted in news making; 2) commercialized media logics bear upon what gets covered and how; 3) the media's production routines, attention and processes are known and political actors adapt their behavior accordingly; 4) media operate as watchdogs, monitoring the democratic process and voicing position for greater accountability; and 5) media constructs the public sphere and controls 
terms of exchange $\left(25^{1-252}\right)$. As the media become central to politics then, they perform democratic accountability by primarily reporting on and at times triggering public formal accountability processes (Jacobs and Schillemans 2016).

Both the politics of the everyday and the Politics of (state) governance play out in the media and audiences use the media to interact with one another and the state. However, the extent to which these interactions are considered political participation depends very much on how power functions in a given society (Carpentier 2011). For instance, Wasko and Mosco (1992) distinguish between participation 'in' the media - the participation of non-professionals in content production and decision-making within media organizations and 'participation through the media' -- the mediated participation in public debates and self-representation where citizens voice their concerns, opinions, experiences and interact with others. This distinction suggests that 'participatory opportunities' are shaped by entrenched "power relations that are not accountable and often not visible within the context of 'normal' politics" (Dahlgren 2011, 90).

Accountability is a communicative process whereby the behaviors of particular actors are evaluated or judged by relevant others, with possible consequences or formal sanctions (Jacobs and Schillemans 2016). Democratic accountability takes many forms. The commonly understood form in democracies is through voting: i.e., elected officials are responsive to the electorate because they want to be re-elected and those who betray public trust are subject to losing office (Chang, et al 2010). Bucy and Gregson (2001), however, observe that the restricted participation implied by this 'minimalist model' (Carpentier 2011) gives officials wiggle room to change their earlier stated policy positions. Citizens must therefore have other means, beside the vote to exact accountability from elected officials and in practice there are other means, both formal and informal. Formal routes include the judiciary, regulatory bodies, etc., and in Ghana, organizations such as the Complaints and Clients Service of Local Government (district assemblies) and the Ombudsman for the Commission on Human Rights and Administrative Justice (CHRAJ) are additional formal spaces of accountability. Informal routes include the media, mass protests, organized action (strikes), etc.

In Ghana, we observe that social networks (e.g., school alumni associations), traditional and religious leaders also function as sources of accountability but they rely on the media to decry and amplify their sanctions. This suggests that public opinion drawn from media coverage has the potential to demand accountability from public officials. Indeed, a 2013 survey of Accra inhabitants $(n=615)$ reported that $34.1 \%$ preferred and used radio more than 
the formal mechanisms of accountability available at the local level of district and municipal assemblies (Selormey 2013). This was largely due to radio's accessibility and perceived effectiveness. The first author's experience detailed in the introduction of this paper shows how difficult it is to get basic information like townhall meeting schedules, much less participate in district and municipal assemblies. Thus, media access and participation expand avenues for citizens to attempt to demand accountability from public officials and institutions. Through radio, social media and mobile technologies, citizens are able to report bad behavior, directly question elected representatives, and have their concerns turned into collective issues that could potentially get resolved.

\section{Ghana's Media History}

\section{Independence era to the 4 th Republic}

Ghana's media history is punctuated by episodes of freedom and suppression. Different governments, civilian and military, have adopted various political and ideological positions about the role of the media and its influence within the society. The first government after independence (circa 1957-6o, led by Kwame Nkrumah) retained state ownership of media and prohibited private ownership of broadcasting and subsequent civilian governments of Busia and Limman adopted "libertarian media policies" that maintained the criminal libel law (in use under British colonial rule) and refused to liberalize the airwaves or allow private investors and operators into the telecommunications sector (Gadzekpo 1997). The military regime, the National Liberation Council (NLC), that overthrew the first government established a new "Ghana Broadcasting Corporation" with the responsibility of undertaking "sound and commercial television," providing "impartial and independent service and affording equal time to all political parties" (NLCD, 226 cited in Gadzekpo 1997, 39). The People's National Defense Council (PNDC) thirty years later introduced repressive policies included regular harassment and imprisonment of journalists and critics of the regime, initiating "a culture of silence" (Gadzekpo 1997, 32).

Indeed, prior to private broadcasting in 1994, post-independent governments regarded broadcasting as a tool for nation building and used nation building as justification for state monopoly (Alhassan, 2005). For Alhassan, these were rooted in the idea that nation building required the promotion of "synchronization and homogenization of thought" (Alhassan, 2005, 217); however, this paternalism waned with the liberalization of airwaves and privatization of 
broadcasting in the 199os. In the early 199os, the Ghanaian economy was liberalized during a return to civilian rule and multiparty democracy (called the 4th Republic) and a new constitution was drafted that ensured the establishment of private media institutions. Current thinking around media policy frowns upon government interference to ensure relative independence for freedom and plurality of ideas. Yet, Alhassan (2005) argues that this way of thinking has allowed the government to relinquish its duty to enhance media access to marginalized communities, an observation that is consistent with the liberal market approach favored by successive governments. This aligns with political economic ideas that regard the state merely as existing to supervise the market while allowing it to structure the society.

\section{Networked Radio Within a Commercial Media Mandate}

In tracing the interplay of technological changes alongside economic liberalization in Ghana's media history, Avle (2011) shows how the establishment of Joy FM and its accompanying website, myjoyonline.com, encouraged a networked public in Accra to participate in a newly forming public sphere in Ghana's 4th Republic. Joy FM's initial introduction of interactive programming through phone-ins and later sMs text-ins in the 199os and early 2000 s were often limited to a class of economically upward citizens (university graduates, bankers, lawyers, entrepreneurs, etc.).While numerous stations have been established since then and mobile and internet technologies access has improved across various social classes, media establishments are still connected to business leaders, well-known lawyers, politicians and government officials who constitute the elite class in Ghana and are regarded as the decision-making strata of the society, even as there appears to be greater interactivity and inclusivity of voices on the air waves (Avle 2015; 2016).

Indeed, broadcasting in Ghana since liberalization has been dominated by private companies and the ownership structure shapes media dynamics, since the very people and groups they are supposed to be monitored own the media (see Mancini, 2012). In a study conducted by Media Foundation for West Africa and Reporters Without Borders, a third of the media were either state-owned or had politically affiliated shareholders. For example, Frederick Blay who is also the Chairperson of the incumbent New Patriotic Party (NPP), Kennedy Agyapong an NPP MP and recently the NPP Ashanti (stronghold of the party) Regional Chairman, and Bernard Antwi Boasiako, AKA Chairman Wontumi, all have stakes in media entities alongside extensive business interests. Kennedy Agyapong regularly appears on his television station and is able to command much attention due to his bombastic utterances and charisma, 
often trending on social media as a result. Both Agyapong and Wontumi have been sued for defamation. ${ }^{2}$

Osei-Appiah (2019) argues that the "logic that guides the production of political news among private radio stations may be... [confining] political discourse to a limited set of views which is not representative of the political reality, project[ing] a narrow view of politics, and curtail[ing] plurality in media content" (p.13). That study provides evidence from Ghana on the tendency of commercial media to be driven by economic logics and demonstrates that practices like privileging controversial politicians or actors with charisma and social capital are often because of their attention power. At the same time, Tettey (2017) argues that mobile phone technologies with their audio-visual recording capabilities have allowed citizens to challenge official narratives through surveillance of elected officials and widely circulated captured incidents of political malfeasance. For instance, citizen recordings have exposed political party violence during elections that were hitherto denied by party leaders (Tettey, 2017). Still, despite the dictates of strong market logics and enmeshed political interests of media in Ghana then, we argue that networked radio maintains potential to intervene as a space for accountability. In what follows, we detail how and where this is visible and the implications for media participation and accountability.

\section{Data and Methods}

We qualitatively analyzed two popular award-winning radio shows on two of Ghana's most important urban radio stations Joy FM and Citi FM: Super Morning Show (SMS) and Citi Breakfast Show (CBS) respectively. Joy FM holds prestige as Ghana's first private commercial station and the flagship of what is arguably now a media conglomerate called The Multimedia Group with television, radio, and internet holdings. It provides an interesting contrast to the younger Citi FM, which started airing 10 years after Joy but is now considered the leading English broadcasting station in Accra. Like Joy FM, the parent company of Citi FM, Omni Media, has holdings in television (Citi TV) and online media, and has partnerships with not just local media across the country but transnational distributors, specifically Multichoice, which is viewed across Africa. ${ }^{3}$

2 See "Kwaku Baako sues Ken Agyapong for defamation; demands GHc25m." Retrieved from https://bit.ly/3g3bEJl and "Ibrahim Mahama sues Chairman Wontumi for defamation, demands G HS5M." https://bit.ly/3mqlwOp.

3 More about both stations and their parent companies, as well as other major ones in Ghana can be found here: https://ghana.mom-rsf.org/en/owners/companies/. 
Morning shows are one of the mainstays of radio in Ghana and every major station has one, with episodes ranging between two and four hours. These morning shows are typically variety talk shows, with pre-set segments anchored by a primary host and, sometimes, a rotating panel of interlocutors in-studio. Joy SMS and Citi CBS are important features of weekday mornings for many in Accra and it is common to hear the voices of hosts and panelists in cars as commuters brave through the early morning rush hour traffic to get to work. Indeed, folks have texted and called into the show on their way to work to make reports about accidents and unusually bad traffic jams.

According to Geopoll, in 2018, Citi 93.7 FM had the largest listenership for an English radio station in Ghana. The Citi Breakfast Show (свs) has been awarded the 'Best Morning Show (English)' by the Ghana Journalists Association four times consecutively from 2016-2019. The primary host, Bernard Avle, was named the ' 2017 Journalist of the Year' and helms the show with a panel of three individuals, whose composition rotate depending on whether the individuals are out of the country, typically for graduate school or professional training. For the majority of the show's airing, the panel included Nana Ama Agyemang Asante, an outspoken feminist who was the lone women's voice for a major morning breakfast show in Accra for a while. However, in 2019 and 2020 she went to the US and the UK for professional training, as did the other longstanding panel member Richard Sky who was pursuing a graduate degree in law in the UK at time of writing. Avle himself was absent for two years in 2014-2015 while he received his MBA in the UK. Other than those years, the show has been spearheaded by Avle since its inception in 2004, unlike the Super Morning Show (SMS) which started in the mid-199os with veteran broadcaster Tommy Annan Forson and has been going through a number of hosts, most prominently, the late Komla Dumor, who left in 2006 for the ввс World Service in London.

The current make-up of the CBS panel at time of writing (2021) includes Kojo Akoto Boateng, the former show producer Godfred Akoto Boafo, Kokui Selormey, and sometimes Nathan Quao. The show's main segments include: an introduction with gospel songs, 'business sense' (inspirational message), a 'newspaper review,' the breakfast edition of 'Citi business new,' 'Kick-off' sports segment, and interviews (in studio or over the phone), 'your money'/tip of the day, discussion (including comments from listeners), a special segment depending on companywide programming, all interspersed with music, advertisements, birthday wishes, and panel banter. There is usually a major topic of the day that can emerge from breaking events, popular listener concerns or newspaper headlines. The show typically lasts about three and half hours. On СвS, the panelists often get into lively debates and the host is known for 
his stinging critiques often directed against state authorities but sometimes to everyday citizens.

Joy 99.7 F M's Super Morning Show won 'Best Morning Show 'and 'Best Radio Program' in 2009 by Chartered Institute of Marketing Ghana. ${ }^{4}$ The current host of the show is Kojo Yankson who lived and worked in the U.K. for a decade before returning to Ghana. He replaced Kojo Oppong Nkrumah who is the Minister of Information for the government of Ghana at time of writing. The rest of the panel consists of Daniel Dadzie (who took over as main host when Yankson was away), Winston Amoah, and Animwaa Anim-Addo, together with a range of broadcasters who join to present various segments. Joy SMs's segments include 'news headline', 'Joy business report', news review, interviews, а ввс World News segment, 'sports center', 'food for thought', 'business minute', 'say it right', and 'agenda'. sms typically lasts approximately four hours and usually contains more ads than CBS. The news review includes both local and international sources. Crucially, both SMS and cBs read from each other's news websites (myjoyonline.com and citinews.com).

\section{Sample}

For this paper, we purposively sampled two episodes per month for each program, spanning the months of March through June, 2020, a total of 16 episodes of 8 each. This yielded approximately 6o hours of talk radio and program analysis. This sampling approach allowed us to vary topics that dominated national conversations and also capture the variety of monthly themes these shows focus on. For instance, in March Citi FM held Heritage Month while in June they hosted the Citi Business Festival. Joy FM had a campaign called \#arivealive that was frequently featured on SMS through the months. Both stations extensively use social networking sites to encourage interactivity and routinely remind listeners to "join the conversation" via social media and read messages posted on Facebook and Twitter, alongside texts sent to announced WhatsApp numbers. Thus, we included in our analysis, public Facebook posts and Tweets for all 16 episodes. While both programs sometimes mention other social media platforms, such as Instagram, the two most consistently referenced throughout the samples alongside were Facebook and Twitter, in addition to WhatsApp messages.

\section{Analysis}

For our thematic analysis, the two authors each listened to eight episodes (four for each station) and wrote out partial transcripts and notes in a shared

4 See the Multimedia Group's awards page https://multimediaghana.com/awards.php. 
document where we both analyzed for emerging themes in an iterative manner. ${ }^{5}$ The first level of analysis noted similarities and differences in the format and delivery of the shows. The second level examined substantive elements of interactivity and their relationship with accountability, specifically, to what extent and how audience participation interacted with the program content vis-a-vis topics discussed and on-air guests. We noted repeated patterns as well as seemingly divergent incidents for the sample. We paid attention to the comments the hosts include from their listeners, who they were, and what their contribution was relative to the topic at hand. For the social media analysis, we looked specifically at the content of tweets and Facebook posts, the exchanges taking place, and the general engagement practices of the programs. Not only were the tweets and Facebook post publicly accessible, but they were also directly referenced by the hosts on air. These observations were situated within our knowledge of the media and political economy of Ghana in the analytic process, as well as our prior studies of both stations, including interviews with hosts where necessary to provide background information for the reader.

Below we first give a detailed view of networked radio in action on these two shows, and then present our findings, organized by 1) key themes related to networked radio and participation, 2) the role of these shows as intermediaries between citizens and public officials, and 3) the implications of their intersection for democratic accountability.

\section{Networked Radio in Practice}

The interplay of live broadcasting with synchronous social media activity characterizes networked radio, and both свs and sMs demonstrate this in practice. Throughout the duration of the programs, listeners are invited to participate directly through the dedicated WhatsApp messaging lines or to contribute on various social media handles. CBs's standard jingle, repeated on all episodes, says "Join the conversation on the Citi Breakfast Show on Facebook at Facebook.com/citi97.3, Twitter at twitter.com/citig73, and Instagram at Instagram.com/citig73, with the hashtag citicbs" (see Fig. 1). Telephone and WhatsApp numbers are read out and tweeted on the official handle of the station. The hosts have a considerable social media presence: as of March 2021, Bernard Avle(@benkoku)had 356, 9oo Twitter followers whereas Kojo Yankson

5 We transcribed verbatim for direct quotes used in this paper. 

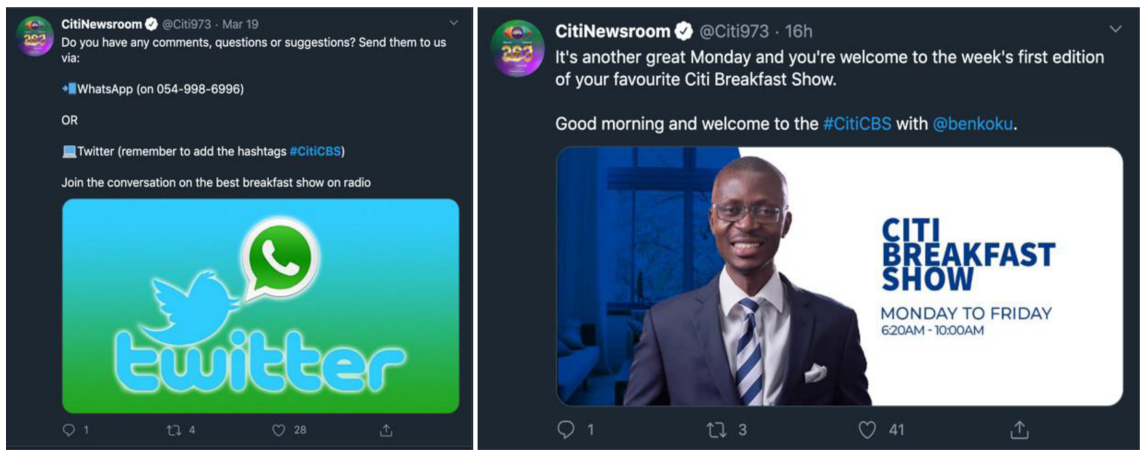

FIGURE 1 Official Citi FM twitter handles displaying multiple modes to interact with the show $(\mathrm{L})$ and a welcome message with an image of the host $(\mathrm{R})$

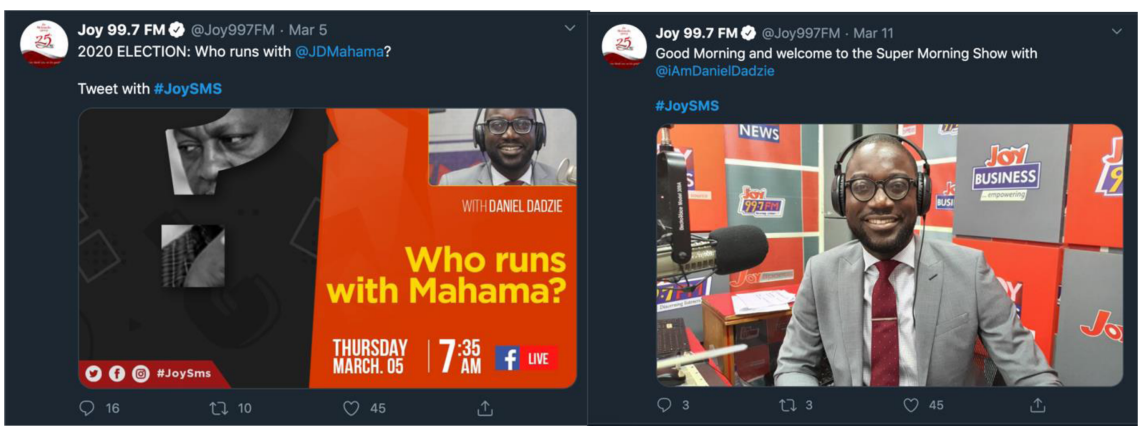

FIGURE 2 Official Joy FM twitter handles displaying a topic question (L) and a welcome message with an image of the host $(\mathrm{R})$.

(@THEKojoYankson) had 84, 8 oo followers. Together with the rest of the panel and the official station handles, they are able to reach a large followership. ${ }^{6}$

Typically, the panels ask listeners direct questions, solicit reactions to in-studio discussions, and sometimes ask specific groups that are affected by an issue to share their experiences (see Fig. 2). For instance, on one episode of SMS, the host says:

If you are a healthcare professional, especially, we celebrate you this morning and the message is still \#isaluteyou. Just mention the name of this doctor, this nurse, this orderly, whoever helped you when you went to the hospital. Say what they did and add the hashtag \#isaluteyou. The

6 Citi FM's official handle @Citig73 has 1.2 million followers on Twitter and Joy FM's @Joy997FM has 1.4 million. The panel members for both morning shows have a range of followers between $28,700-154,6$ oo for CBS and 1,500 - 84, 900 for SMS. 
number is 0244340437. You can also tweet with the hashtag, 'joysms', and that your message... We will surely read on the show as we celebrate frontline health workers. (MYJOYONLINE, APRIL 6, 2O2Ob, 38:20)

Both shows have dedicated segments focused on what is trending on social media. In свs's segment, Tech and Social Media Trends, one of the panelists goes through the topics and hashtags trending on Twitter and offers brief commentary. In the episodes included in this paper, the trending topics often correlated with the most popular entertainment and political topics and discussions taking place in the country. Trending topics were as varied as they come: the arrest of a pastor for making threatening statements against the Electoral Commission chair Jean Mensa; Wendy Shay's (a singer) walkout of an interview over sexist questions; famous pastor Duncan Williams' son's explicit video; and musician Stonebwoy's Anloga Junction album release. On occasion, trending topics have been the main topic of the show's discussion, evidence not only of the agenda setting potential of social media, but the attentiveness of broadcasters to online conversations.

It is also common to see the shows' hashtags (\#CitiCBS and \#JoySMS) trending on Ghanaian twitter when they are on-air, a testament to their popularity and their ability to elicit engagement on social media.

Reading listener comments from WhatsApp and other social media platforms are a core part of both SMS and CBS, although the format is loose: the name of the listener, which part of Accra or Ghana or the world they are writing from, and the message or question they have. с вs frequently reads comments but rarely speaks to listeners live. Prior interviews with the panel indicate that they refrain from voice calls due to the persistence of "serial callers" on the Ghanaian airwaves. The свs panel appears to be of the view that there is far less control on the caller switchboard than there is in selecting which posts to read given the tools they have at their disposal.

sMs, on the other hand, has a regular dedicated segment where listeners call in and speak on-air with the hosts. The segment is promoted in a way that encourages listeners to continuously stay tuned while they listen to other segments of the show, interspersed with frequent ads. For instance, the host announces "...we want to hear from you and we want to hear from you right after these important messages" [ad plays] (Myjoyonline June 11, 2020c, 2:35:42). Tweets are often read out as well and as an example, the June 11, 2020 SMS segment aired 11 calls and read 5 tweets about 2 hours 40 minutes into the episode. Calls lasted between one to three minutes, with callers identified by name and location and most of them appeared to be men. The topic for the calls was set by the hosts but at times, callers would bring their own concerns 
to the attention of the panel. In a typical call, the host exchanged pleasantries with callers to build rapport and at times sounded like a customer service representative receiving complaints on behalf of the state. Here is a typical exchange:

Kojo: Let's go to Adenta [location], here's George. Good morning, George. George: Yeah, good morning.

Kojo: Thank you, sir, for calling us. George, so you've heard a lot, what are your thoughts on this? (MYJOYONLINE JUNE 11, 202Oc, O3:07:36)

The listener airs his concerns, Kojo thanks him, and moves on to the next call.

Both shows are archived as podcasts online, making it possible for time shifted audiences to listen without the live interaction. International listeners can tune in live via radio streaming apps and dedicated websites. Citi FM has a dedicated mobile app that offers live streaming. In addition, CBS offers a Facebook video live stream of the newspaper segment where listeners can see the hosts and comment in a multimedia environment. This stream is later archived on their YouTube channel, CitiTube (Fig. 3). sMs also archives various segments available on Facebook and YouTube but updates it less frequently (Fig 4).

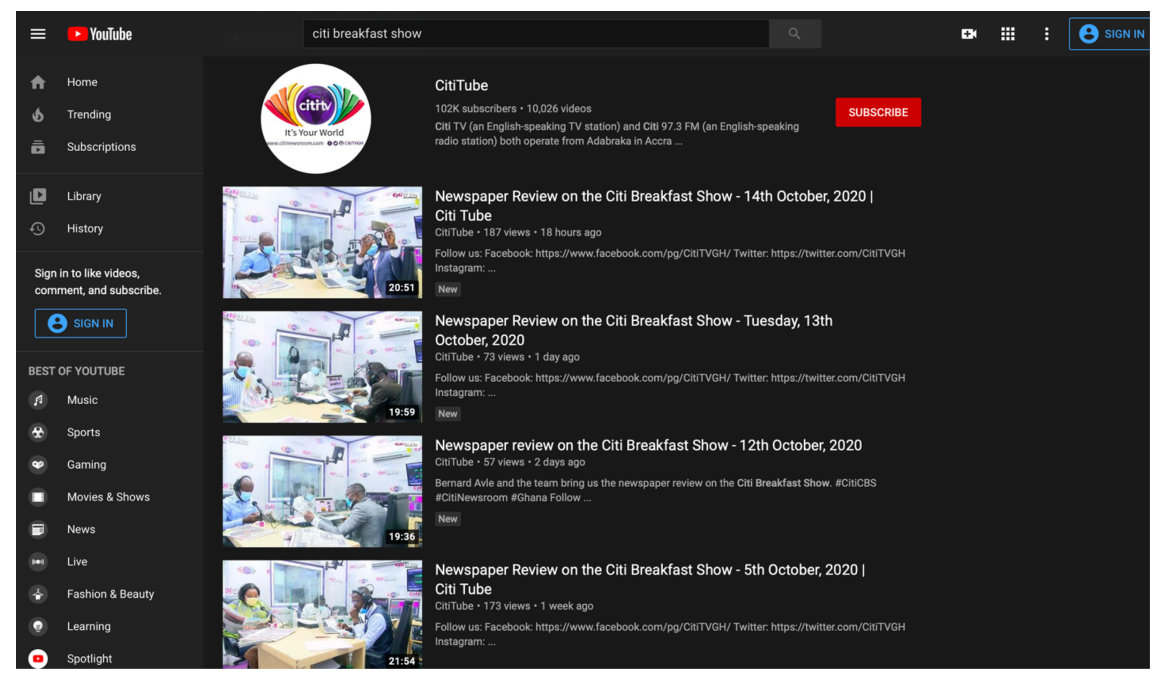

FIGURE 3 A screenshot of Citi FM's YouTube channel showing clips of recently aired CBS newspaper segments. Note the newspapers being read live on-air by panel members $(\mathrm{L})$ while the host $(\mathrm{R})$, moves between the papers, his laptop, and mobile phone. 


\section{Intermediaries Between Public Officials and Their Constituents}

Our analysis shows that discussions on CBS and SMS mainly followed the major news items reflected in both stations' own coverage as well as newspaper and online news review that they do early in the program (Fig.4) and on their social media pages (Fig. 5). This "recycling of content", described by Bagga-Gupta and Rao (2018) as "content-chaining" (25), is created by following newsworthy items and reflects the commercial impetus behind the stations and their prioritization of political and business news as part of their brand.

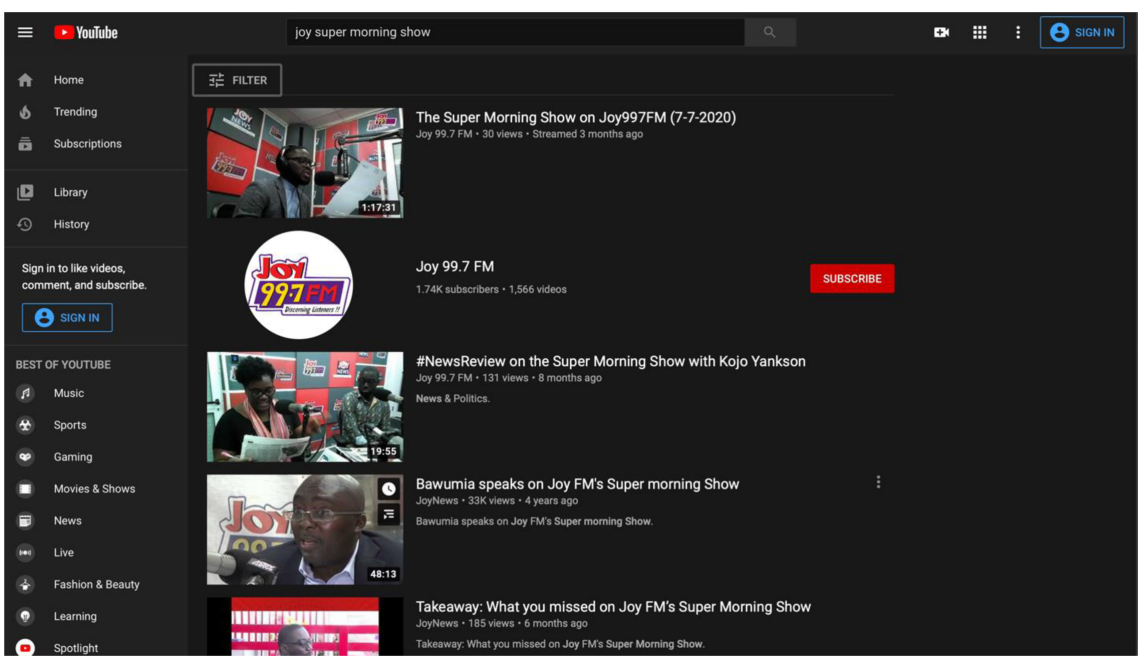

FIGURE 4 A screenshot of Joy FM's YouTube channel showing clips of recently aired SMS segments and full shows.
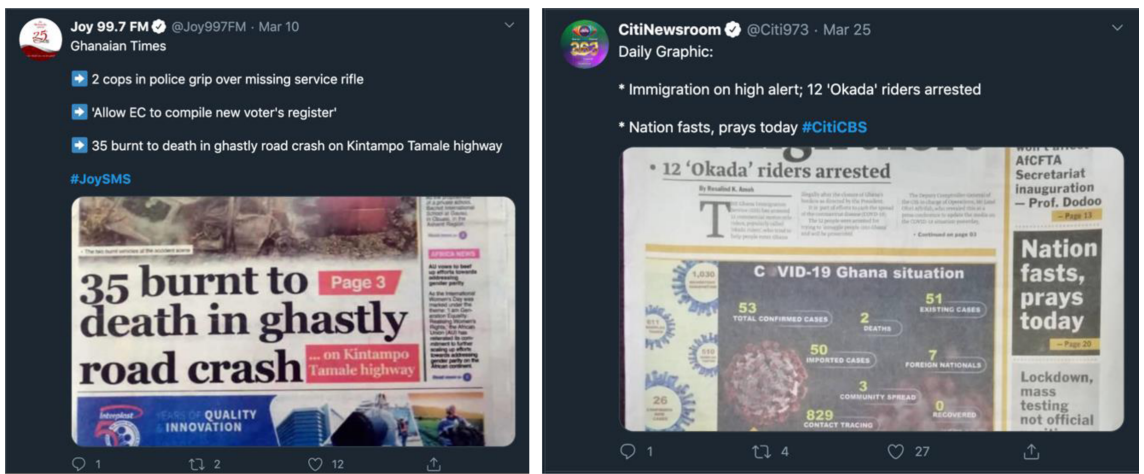

FIGURE 5 Screenshots of newspaper reviews on the official Twitter handles of Joy FM (L) and Citi FM (R). 
A second source of topics came from their listeners whose concerns often mirrored major events, such as local flooding, breakdowns of public services like the interruption of water supply, or global issues like the Covid-19 pandemic. The overall bent of the programs we examined centered around providing additional details and angles to the chosen topic(s) of the day, reaching out to experts to explain technical issues, and amplifying listener concerns that are shared through the interactive modalities described in the previous section. Frequent complaints about an issue would sometimes prompt CBS to dedicate an entire show to the topic. For instance, on numerous occasions the show focused on the popular topic of bad roads. In the June 10 episode, text messages about bad roads flooded the show as the host declared, "we're talking roads, rains, and drains" (Citi97.3 June 10, 2020b, 44:45). If it is an ongoing or long-standing issue, the topic will resurface another day, and when it is the focus, the panel 1) provides additional information and explanations, either through calling/bringing in an expert or the responsible public official and 2) discusses the matter, asking questions, and injecting their own opinions and expertise.

Given the high profile of both radio stations, journalistic access to experts and public officials enables the hosts of свs and sмs to access 'insider' information on the politics of distribution of public services and other issues in Ghana. Listeners know that politicians respond to public outrage and thus often use radio to amplify their concerns via these shows. Frequently, the hosts would mention receiving several messages on a particular matter and solicit for additional comments from listeners. For instance, on the April 16 edition of Свs, the panel mentioned that even before the show began, they had received several messages about water shortages in Accra. They read several of these messages on air, naming the different parts of Accra they come from to underscore that it was a citywide problem. ${ }^{7}$ They do this largely because they know the public officials responsible for this utility are listening and continue to scale up the complaints as the show progresses. In a prior episode, the cBs host commented that the Ghana Water and Sewerage Corporation (GWSC) was the most responsive of public entities: "the water people are pretty responsive. I don't know if it's me, but they are really good. They either give the number of the person in charge or they give a situational report" (Citi97.3 March 25, 2020c, 1:16:0o). A panel member provides additional information that the GWSC website has names of general managers and contacts for the public to reach out directly. This is consistent with other episodes in which panel members often

7 We did not have access to the WhatsApp messages sent to either program. 
conduct research on the fly in response to the discussion, providing additional information for listeners and each other in studio.

In addition to surfacing the concerns of listeners, these shows sometimes take particular institutions to task on air ( СвS) or give feuding institutions the chance to have their say and defend themselves to the public (SMS). In other cases, the panels locate experts and public officials and bring them on air to explain the issue and provide answers to the public. In one episode of с $\mathrm{BS}$, the host explains their method for triaging concerns sent to them:

... people send us a lot of things we can't deal with immediately. Guys, we've received all those things. Some of the things you sent us, especially the newsroom, they systematically follow up so you may not hear me say something about it on air because we want more information. Sometimes we do tv news, sometimes we do Citi news, other times we give it to other platforms like Point of View, sorry, Point Blank with Umaru Sanda. So please don't get frustrated when you send us something about something somebody is doing and you don't hear me talk about it immediately... there's a method to the madness. (CITI97.3, MAY 29, 2020d; 13:25-53)

At other times, the stations took action on behalf of the public as a result of an issue discussed or created a campaign in response to a public crisis. This is visible in Citi F M's 2019 'War Against Indiscipline' and Joy FM's 2020 'Arrive Alive' campaign, both of which were cross-promoted across their parent companies' media holdings. Both stations also routinely take on public service roles; Citi for instance created PSA s about Covid-19 in local languages and distributed them via WhatsApp messages and loudspeakers mounted on vehicles in public places. While these intermediary roles performed by these stations help address issues of public concern, they do so in part because citizens are unable to directly access public officials to demand solutions. Stepping into such an intermediary role is thus a double-edged sword as it normalizes the distance between citizens and their elected officials even as it functions as a solution to the immediate challenge of access and accountability.

\section{Gatekeeping Shortcuts and Elite Connections}

The imagined audiences for Joy and Citi are a mix of the middle to upper classes and the upwardly mobile urban dweller (Avle 2015; 2016). From the episodes we listened to, listener contributions come from people who live all over Accra as well as larger cities that the shows are syndicated in, both within and outside the country. The most 'passive' mode of participation (Bucy and Gregson 2001) came from the many birthday wishes that presenters read from people. 
These particular, low stakes messaging typically bore both male and female names and we often heard birthday wishes for children and spouses. However, substantive commentary from listeners towards topics being discussed were overwhelmingly male - both in the voice callers on SMS and the texts read on Свs. This raises the question of how messages are selected to be read, particularly as the hosts and the majority of panels are male.

There appeared to be no clearly defined guide for which comments are selected, perhaps outside of those that are clearly offensive or vulgar. Yet, we discerned what we refer to as 'gatekeeping shortcuts' at work; that is, hosts resorted to reading comments from people they could quickly identify given the constraints of airtime and simultaneously managing face -to-face interactions, social media feeds, text messages and phone lines, all while speaking live. We identified two groups that were frequently relied on when taking such gatekeeping shortcuts: frequent/serial panelists from civil society groups who may be known to listeners and individuals from their personal networks. For instance, on the June 11, 2020 episode of sMs, the host read a Facebook post from Kofi Bentil, a fairly well-known lawyer and prominent social commentator who works with Imani Africa (a partner of the Koch Foundation backed Atlas Network, an American libertarian think tank) that frequently gets airtime on various radio stations. He reads Bentil's post and adds it to the studio discussion on the reopening of schools amidst the Covid-19 pandemic:

Dear minister of education, before you take our kids into school. Please 1) test everyone before they are admitted; 2) test all teachers before they start work; 3) House all teachers in school so they don't go in and out of school and bring infection to the kids. Note this, if one student gets it, they will all get it and bring it home. Please, please, test before admission and test after vacation. Medaase. ${ }^{8}$ (MYJOYONLINE, JUNE 11, 2020c, 03:53:07)

Here Bentil's opinion gets read into the show because of his notoriety and familiarity to the sMs panel. On the June 10 episode of Свs, the host reads a message in relation to project allocations by members of parliament, saying:

So, one of my friends says "the MP will first look at his voter base to determine where to take the projects. They will never lobby projects to places where voters vote outside the constituency. Santor is [a] new

8 'Thank you' in Akan. 
development and new settlers. They are also outside voters, so they don't matter to the MP of the area. (CITI97.3 JUNE 10, 2020b, 54:58)

He does not name this friend but that person is presented as an insider on election politics.

The people that make up the two groups that appear when hosts take gatekeeping shortcuts tend to be similar to the identities of the hosts: university educated (dominantly) male voices embedded in business, politics, and technocratic industries. Relying on familiarity to ease the strain of simultaneously attending to multiple media and various social interactions, these hosts end up privileging the voices of a relatively small elite group of people relative to the Ghanaian population. While there seemed to be an effort to read comments from diverse locations across the city and country, presumably to give a broad representation of their listeners, these gatekeeping shortcuts undercut those efforts by amplifying those with greater social and ideological proximity to the hosts.

\section{Language and Languaging}

Ghana is a multilingual country with English the official language of government and of instruction in schools. As is often the case with former European colonies, English has come to stand in as a marker of education and therefore social class (Adika 2012; Wa Thiong'o 1994) even if other languages like Akan are the lingua franca in major cities. In fact, despite the fact that Accra's most listened to station is an Akan broadcasting one, Peace FM, and the fact that local language stations do the important work of translating official government discourse to the 'average Ghanaian', English-language stations are associated with a technocratic class and the world of the upwardly mobile. It is in this context that networked radio takes on additional importance, specifically because English is also the language of the internet and therefore limits media participation to a literate class of people.

As Bagga-Gupta and Rao (2018) have shown, merely speaking or being literate in English is not enough online, one must also have digital language literacies, for instance knowing social media and platform conventions such as hashtaging in order to effectively participate on networked radio. For instance, to optimize chances of being seen, listeners tag the accounts of the hosts of свs (@benkoku), their panel members (@KojoAB, @nathan_quao, etc.), the official station (@Citi973) and the shows' designated hashtag on Twitter (@CitiCBS). This languaging is especially important because of the "localchaining" (Bagga-Gupta and Rao 2018) that occurs between social media and 
on-air presenters. For instance, the official station handle (@Citi973) and sometimes the hosts and panel members retweet свs listeners, even if they were not read live on air or seen during the live show. This turns listeners' participation into an asynchronous one that lives on as long as the social media posts are archived (Avle 2016), becoming part of the larger discourse and community, shaping public discourse in new ways. This digital literacy favors a youthful audience, given the relatively short time that social media has been a part of the media landscape in Ghana.

On air, when messages sent to the shows are not crafted in standard English or contain grammar errors, we heard the hosts and panels faltering as they read, and sometimes reprimanding the writer for not being clear. In one instance, the CBs host reminds listeners "...please write properly so I can read it” (Citi97.3 June 10, 2020b, 2:30:00). In other instances, such as observed on sMs, a caller is cut off mid-sentence when they are unable to communicate clearly and succinctly. On occasion hosts will correct the grammar of text messages and texts are sometimes rephrased to make them sound "civil". sms even has a segment called 'Say it right', dedicated to teaching corrections to common English mistakes. For example, the June 11, 2020 episode featured a lesson on the incorrect popular phrase "I am doing good" versus "I am doing well." This is a somewhat unique feature to SMS but contributes overall to the classist use of the English language on-air in this multilingual society that signals a bias towards elite communication (see also Avle 2015). This elite bias for English language use suggests that non-elites and other groups of listeners may not feel comfortable contributing and indeed reflects a broader attitude in which students have been punished in schools for speaking their local languages outside of their lesson time (Boampong 2013).

Language proficiency and literacy, in both English and the digital, gives one access not only to official government discourse but also to the elite criticism on these programs that collectively mark public discourse. In other words, the ways in which English is used on air and online signals a class preference that, on the one hand, gives the show prestige and therefore makes it easier to draw public officials on board, but on the other hand, function as exclusionary to non-English speakers, non-literate listeners, and those at their intersections. This is where these programs are caught between the emancipatory promise of building a plural public sphere, and the burden of making the state less opaque to its people. We characterize this as being caught between hogging the mic (by elites) and passing it to the rest of the listening public who frequently use these shows as a means to reach their public officials. 


\section{Discussion: Passing Versus Hogging the Mic}

Networked radio provides the space for citizens to access the political system, politicians, public officials and institutions through mediated encounters. This mediation is double: first, through language use and languaging that takes place on-air and online, and second, through the intermediary advocacy work that particular stations and journalists do. Not all radio stations intervene in civic matters, even if many allow listeners to voice their opinions. This difference is key as both Joy FM and Citi FM position themselves as non-partisan political and business focused stations. Through these engagements, citizens are better informed and are able to amplify their concerns to public officials and fellow citizens. This amplification works as a mechanism for accountability as it often requires public officials to show up and defend themselves to the public, and in some cases, actually attempt to resolve problems such as disruption in utility services, breakdown of public infrastructures, etc.

Taking public officials to task through radio stations has become a favored route for citizens as the formal routes (for instance through local assemblies) are either unknown to the public or do not function as they should. The social media component of networked radio similarly gives audiences access to the hosts of these shows, themselves elites with proximity to other elites (like government officials and experts) who are typically at a distance from the listener. The addition of social media to live radio broadcasts means that listeners have asynchronous access to the hosts and can continue conversations or start new ones that may or may not make it to the live broadcast (Avle 2016). It also means greater access to people who may be able to provide insight into public issues that simply listening to them live does not allow, and it expands the audience to include those in the diaspora.

The necessary gatekeeping that facilitates live broadcasting flow of networked radio however complicates both this process of participation and its associated benefits towards public accountability. Specifically, our findings demonstrate that shortcuts taken to include commentary invariably veers towards homophily -- specifically, individuals who are socially and ideologically proximate to the hosts of the radio shows get their comments selected, in part because they are known/familiar and hosts can judge with ease that their comments will aid the flow of the ongoing conversation.

The complication we draw attention to here is that these radio stations provide one of the few alternatives to voting that allow citizens to demand and obtain accountability from their elected officials and to collaborate with others towards civic action. By acting as intermediaries, these programs and hosts 
connect 'a speaking public to an unhearing state' (Srinivasan and Diepeveen 2018). Thus, when public discussions veer toward amplifying the opinions of particular classes and ideologies, it underscores how tenuous such a space is for participatory democracy in general and underlines the need for multiple venues for accountability.

Indeed, the fact that these are private commercial radio stations suggest that the media are in their right to select whomever they wish to put on air. However, in listening to these shows, there appears to be tacit a agreement between presenters and listeners that "they are in it together." The tenor of conversations on air is of joint frustration at failures of public infrastructure, such as the often-discussed state of the roads, and hint at building mutual support towards making the democracy in Ghana work when the idealized version does not seem tenable. There appears to be a shared investment in making this alternative route work for the social realities they share and these programs and their listeners together attempt to shape public accountability where limited avenues exist. Indeed, when the issue is about everyday problems, both CBS and SMS appear to privilege messages from diverse neighborhoods in Accra and Ghana to represent various socio-economic statuses.

Our critique focuses on the ideological bent of the elite commentators (such as the example of Kofi Bentil's Facebook post read on Joy SMS), who through the two mechanisms we identified (social media posts and through personal connections with presenters) tend to favor neoliberal viewpoints and often echo the predominantly western funded think tanks such as Bentil's (Imani Center for Policy and Education) that now dot the civil landscape, particularly around discussions on the economy (Hearn 2001). Under the guise of research, they also push reports that align with their ideological commitments and these reports can have a strong bearing on media discussions. They compete with non-elite listeners for the attention of the hosts and with large followership (the President of Imani, Franklin Cudjoe has over 84k followers on twitter, Kofi Bentil's has more than $36 \mathrm{k}$ following on Facebook), presenters are likely to lean more on their gatekeeping practices to 'keep the show going'. In doing so, they inadvertently overrepresent the neoliberal and technocratic viewpoints that these think tanks and individuals espouse, making it hard to hear others, say leftist or socialist politics (see Hearn 2001).

Beyond ideological bent, the rising phenomenon where other elites and wellknown social commentators like lawyers, academics, etc. interject more into discussions means that the lens that the everyday concerns covered can sometimes be framed through the lived experiences of those elites. For instance, in a number of episodes about fixing roads (such as the June 10 episode of СвS in 
our sample), the dominant thread came from those worried that their personal cars sustain damages and wear out faster than normal. An alternate frame that would be more relevant to the majority of Ghanaians who do not own personal vehicles, would have focused on the state of public transportation and perhaps the impact roads have on their routes and accessibility. (Admittedly, the show has also tackled the broader problem of safe and comfortable public transportation in other episodes). The point here is that elite commentary changes even the space that we perceive to be geared more for non-elite listeners of the show through the lens that is used to analyze the issue.

At the same time, access to elites is what enables these shows to do their advocacy and work as intermediaries well, enough for listeners to trust them with their problems. A key finding is that these journalists and program hosts have unprecedented access to public officials, unlike the 'average Ghanaian'. This means that when experts are needed or insider information is required to help the public, they are able to reach into those same elite networks that we problematized above, to provide solutions that listeners do not have immediate access to. Being an intermediary thus requires balancing the needs of your diverse listenership, to show that you can use your access to inform and support when needed. But this mode of accountability is limited in its effectiveness as elected officials are sensitive to voting patterns and use the media to amp their efforts in election years to boost their image. In off-cycles, those with a modicum of shame may respond to public censure but those without it may simply ignore any attempts to publicly take them to task for negligence or wrongdoing. Accountability, then, is not guaranteed as the hosts themselves have on occasion expressed frustration at covering and dealing with recurring issues for some time.

Increasingly, radio stations in Ghana actively take on public advocacy work: from submitting petitions to coordinated campaigns to address national or local challenges. Extending Clark's (2018) use of Fanon's ideas about culture and social changes, we observe that journalists appear active in a 'protest stage'. This is where the act of accountability is using social commentary and various forms of advocacy like petitions to hold public authorities accountable. Yet, the 'combat stage', where they work towards mobilizing the people to engage in the work of social transformation appears to be less feasible. In the past, some journalists have been charged with 'inciting the public' after encouraging people to mobilize and demand accountability by directly going to public officers and institutions. The CBS host, who is also the general manager for Citi, on occasion opines on how they see themselves within the media scape of Ghana and the reasons for their advocacy. On the April 28 episode of Свs, he says: 
Our job is to expose the truth, we will do that fearlessly, we'll do that honestly, but we also help people to have a reference point ... the media's job is not just education and information but also entertainment and that connotes relaxation, that connotes positive feelings, that connotes happiness [39:10].

Here, he alludes to the balancing act that a commercial media entity must take on in a democratic state: take on the work of the fourth estate, as a conduit of accountability, while also providing lighter fare to maintain good feelings and ultimately stay profitable. This tradeoff parallels the one presented by the increased inputs of networked radio on production behaviors and the reliance on gatekeeping shortcuts to maintain liveness. To act as an intermediary and alternate route through which citizens hold public officials accountable, they must at times pass the mic to the everyday listener to air their grievances and then pass it to the elected officials to remedy the situation. Other times, by dint of the exigences of running live shows alongside active social and new media activity, presenters make decisions that effectively keeps the mic in between the elite groups of society, one that is of the same socioeconomic class as they are, essentially over representing their viewpoints and concerns and allowing them to 'hog the mic'.

\section{Conclusion}

In this paper, we have argued that network radio has become an important feature for enacting democratic accountability in Ghana. Improved access to the political system and its actors allows citizens to bear witness, make demands, and challenge government narratives. It has expanded access to democratic participation in ways that impact the accountability of public institutions, political systems and officials, elected or otherwise. Networked radio has enhanced political participation through the media and listeners with access are able to voice their opinions and concerns more readily, with the chances that their concerns and opinions will be amplified on the media platforms vastly improved in addition to being able to shape public discourse in new ways.

Of course, the affordances of networked radio and their attendant vehicles for democratic participation do not operate outside the existing relations of power, for instance who owns and operates the media. Indeed, as we have noted, elite commentary through various production practices and constraints at times dominate the way media discussions unfold, particularly in the way 
they determine the limits of the debate space. At the same time, those same elite sensibilities are what allows these programs to even get public officials to respond and to be held accountable when necessary. An additional tension is how commercial concerns among other pressures, also shape who holds the mic, when, and for how long.

In general then, increased reliance on these potent interactive spaces produced by private media may be impacting other public democratic accountability forums in profound ways. Specifically, other mechanisms of accountability may continue to be weakened or underutilized as citizens come to over rely on radio to act as an intermediary between them and the state. Given their importance as a forum for accountability, and their potential to encourage direct public forms of engagement with public institutions, networked radio can potentially devote energy towards improving other spaces for accountability. This would lessen the increased burdens of their intermediary role but also slow down the shift towards (unintended) elite capture in civic accountability. Invariably, networked radio contributes a shifting of the fundamental power relations between citizenry and elected and what happens next helps determine how robust a tool media participation can be for democracy.

\section{References}

Adika, Gordon. 2012. English in Ghana: Growth, Tensions, and Trends. International Journal of Language, Translation and Intercultural Communication, 1, 151-166.

Afrobarometer. 2018. "AD250: Ghanaians rely on radio and TV, but support for media freedom drops sharply." Accessed October 10, 2020. URL: https://afrobarometer. org/publications/ad25o-ghanaians-rely-radio-and-tv-support-media-freedomdrops-sharply.

Alhassan, Amin. 2005. "Market valorization in broadcasting policy in Ghana: Abandoning the quest for media democratization." Media, Culture \& Society 27(2): $211-228$.

Avle, Seyram. 2011. "Global flows, media and developing democracies: The Ghanaian case."Journal of African Media Studies. 3 (1): 7-23.

Avle, Seyram.2015. "Networked radio: The role of social media interactivity on radio broadcasts in Ghana." International Communication Association 65th Annual Conference.

Avle, Seyram. 2016. “Radio locked on @Citi973." In: Wendy Willems and Winston Mano. 2016. Eds. Everyday media culture in Africa: Audiences and users (Pp. 161-179). New York: Routledge. 
Bagga-Gupta, Sangeeta, and Aprameya Rao. 2018. "Languaging in digital global SouthNorth spaces in the twenty-first century: media, language and identity in political discourse." Bandung:Journal of the Global South. 5 (1): 1-34. https://rdcu.be/NbDk.

Boampong, Cyrelene Amoah. 2013. "Rethinking British colonial policy in the Gold Coast: the language factor." Transactions of the Historical Society of Ghana. (15): 137-157.

Bucy, Erik P., and Kimberly S. Gregson. 2001. "Media participation: A legitimizing mechanism of mass democracy. New Media \& Society. 3(3): 357-38o.

Carpentier, Nico. 2011. Media and participation: A site of ideological-democratic struggle. Bristol: Intellect.

Chang, Eric CC, Miriam A. Golden, and Seth J. Hill. 2010. "Legislative malfeasance and political accountability." World Politics. 62 (2): 177-220.

Citi97.3. 2020a. "Citi Breakfast Show Tuesday 9th June 2020." Audio, 03:33:51. URL: https://soundcloud.com/citi97-3/citi-breakfast-show-953066ogo.

Citi97.3. 2020b. "Citi Breakfast Show Wednesday 1oth June 2020." Audio, o3:33:51. URL: https://soundcloud.com/citig7-3/citi-breakfast-show-wednesday-june-102020.

Citi97.3. 2020c. "Citi Breakfast Show 25th March 2020." Audio, 3:34:O2. URL: https:// soundcloud.com/citig7-3/sets.

Citi97.3. 2020d. "Citi Breakfast Show- Friday May 29, 2020." Audio,o3.29.26. URL: https:// soundcloud.com/citi97-3/citi-breakfast-show-friday-may-29-202O.

Clark, Msia Kibona. 2018. Hip-hop in Africa: Prophets of the city and dustyfoot philosophers. Ohio: Ohio University Press.

Coker, Wincharles. 2012. "Mobile communication and the culture of self-expression: The case of SMSing to radio in Ghana." Journal of Media and Communication Studies 4 (6): 123-133.

Dahlgren, Peter. 20o9. Media and political engagement. New York: Cambridge University Press.

Dahlgren, Peter. 2011. "Parameters of online participation: Conceptualising civic contingencies." CM Komunikacija i mediji 6, no. 21: 87-109.

Hearn, Julie. 2001. "The 'uses and abuses' of civil society in Africa." Review of African political economy 28 (87): 43-53.

Gadzekpo, Audrey. 1997. "Communication policies in civilian and military regimes: The case of Ghana." Africa Media Review Vol. 11 No. 2. 1997

Geopoll (2019). “Ghana Top Shows on TV \& Radio, 2018.” URL: https://cdn2.hubspot. net/hubfs/325431/Ghana\%2omedia\%2odata\%202018\%2ofinal.pdf.

Jacobs, Sandra, and Thomas Schillemans. 2016. Media and public accountability: typology and exploration. Policy \& Politics, 44(1), 23-40.

Loader, Brian D., and Dan Mercea. 2012. "Networking democracy? Social media innovations in participatory politics." In Social Media and Democracy, edited by Brian D. Loader and Dan Mercea, 12-21. Routledge. 
Mancini, Paolo. 2012. Instrumentalization of the media vs. political parallelism. Chinese Journal of Communication, 5(3): 262-280.

Mazzoleni, Gianpietro, and Winfried Schulz. 1999. "Mediatization” of politics: A challenge for democracy?. Political communication, 16(3): 247-261.

Myjoyonline. 2020a. "Super Morning Show." March 5, 2020. Audio, 4:08:47. UR L: https:// www.myjoyonline.com/podcasts/?show=joy_super-morning-show.

Myjoyonline. 2020b. "Super Morning Show." April 6, 2020. Audio, 04:O3:45. URL: https:// www.myjoyonline.com/podcasts/?show=joy_super-morning-show.

Myjoyonline. 2020c. "Super Morning Show." June 11, 2020. Audio, O4:O3:45. URL: https:// www.myjoyonline.com/podcasts/?show=joy_super-morning-show.

Osei-Appiah, Sally. 2020. "News Media Logic and Democracy: Strange Bedfellows in Political News-making Practices of Private Radio Stations in Ghana." African Journalism Studies. 40(3): 57-72.

Page, Benjamin I., and Jason Tannenbaum.1996. Populistic deliberation and talk radio. Journal of Communication, 46(2): 33-54.

Philp, Mark. 2009. "Delimiting democratic accountability." Political Studies, 57(1), 28-53.

Selormey, Ernestina Edem. 2013. "Citizen voice and bureaucratic responsiveness: FM radio phone-ins and the delivery of municipal and local government services in Accra, Ghana." PhD dissertation, Institute of Development Studies, University of Sussex, U.K.

Srinivasan, Sharath, and Stephanie Diepeveen. 2018. "The power of the 'audiencepublic': Interactive radio in Africa." The International Journal of Press/Politics, 23(3): $389-412$.

Tettey, Wisdom J. 2017. "Mobile telephony and democracy in Ghana: Interrogating the changing ecology of citizen engagement and political communication." Telecommunications Policy. 41(7-8): 685-694.

Wa Thiong'o, Ngũgĩ. 1994. Decolonising the mind: The politics of language in African literature. Nairobi: East African Publishers.

Wasko, Janet and Vincent Mosco. 1992. Democratic Communications in the Information Age. Toronto \& Norwood: Garamond Press \& Ablex. 